\title{
Microbiology of Methicillin Resistant Staphylococcus Aureus: A Review
}

\author{
Iddah, M. Ali $^{1^{*}}$, Peter K. Nyongesa ${ }^{2}$ \\ ${ }^{1}$ Department of Medical Microbiology and Parasitology, School of Medicine, Masinde Muliro University of Science and Technology, \\ P.O. Box 190-50100, Kakamega, Kenya \\ ${ }^{2}$ Department of Medical Microbiology and Parasitology, School of Medicine, Masinde Muliro University of Science and Technology, \\ P.O. Box 190-50100, Kakamega, Kenya
}

$\begin{array}{cl}\text { Article History } & \text { Abstract: Staphylococcus aureus (S. aureus) is a gram positive organism that serves as an } \\ \text { Received: } 21.01 .2021 & \begin{array}{l}\text { opportunistic pathogen and frequent colonizer of the epithelium causing severe diseases in } \\ \text { human and animals. The widespread use of antibiotics both in human and Veterinary } \\ \text { Accepted: } 04.03 .2021\end{array} \\ \text { Published: } 22.03 .2021 & \begin{array}{l}\text { Staphylocoscus aureus } \text { (MRSA) is a common bacterial pathogen responsible for a variety of } \\ \text { infections. Resistance to methicillin is determined by the mecA gene, which encodes the }\end{array} \\ \text { Journal homepage: } & \begin{array}{l}\text { low-affinity penicillin-binding protein PBP 2. Lately, new methicillin resistance gene, mecC } \\ \text { has been discovered from humans, animals and food products. MRSA infection was first } \\ \text { considered hospital-associated (HA-MRSA) and community-associated MRSA (CA- } \\ \text { https://www.easpublisher.com } \\ \text { MRSA) infections. However, another group emerged known as livestock-associated MRSA } \\ \text { (LA-MRSA). The isolation of MRSA from different species, food products and the } \\ \text { environment raised concern on the role of animals particularly livestock and wildlife in the } \\ \text { epidemiology of MRSA. The spatial distribution of MRSA indicates interspecies } \\ \text { transmission and colonization of different populations. This review summarizes the } \\ \text { epidemiology, current knowledge, genetic mechanisms, and transmission pattern of MRSA, } \\ \text { and colonization. }\end{array}\end{array}$

Keywords: Genetic Mechanism, Epidemiology, HA-MRSA, CA-MRSA, LA-MRSA, Transmission, Colonization.

Copyright (C) 2021 The Author(s): This is an open-access article distributed under the terms of the Creative Commons Attribution 4.0 International License (CC BY-NC 4.0) which permits unrestricted use, distribution, and reproduction in any medium for non-commercial use provided the original author and source are credited.

\section{INTRODUCTION}

In 1959, shortly after the introduction of methicillin, a semisynthetic beta-lactamase resistant penicillin, isolates resistant to this agent were also reported. Outbreaks of methicillin-resistant Staphylococcus aureus (MRSA) infections occurred in Europe in the early 1960s [1]. Since these original descriptions, MRSA, as well as coagulase negative staphylococci (CoNS), which are commonly resistant to methicillin, have emerged as major nosocomial and community acquired pathogens. There have been three pandemic MRSA clones which have been traced back to the original 1959 MRSA isolates in Denmark and England [2]. In addition, molecular typing of MRSA strains collected from many geographic areas has revealed that by 2002, five major MRSA clones emerged worldwide [3]. The more recent epidemic community-associated MRSA strains appear to have emerged from earlier epidemic clones [4-6].

Methicillin-resistant Staphylococcus aureus (MRSA) are a type of staphylococcus or "staph" bacteria that are resistant to many antibiotics. Staph bacteria, like other kinds of bacteria, normally live on the skin and in the nose, usually without causing problems. MRSA is different from other types of staph because it cannot be treated with certain antibiotics such as methicillin. Staph bacteria only become a problem when they cause infection. For some people, especially those who are weak or ill, these infections can become serious.

MRSA infections are more difficult to treat than ordinary staph infections. This is because the strains of staph known as MRSA do not respond well to many common antibiotics used to kill bacteria. When methicillin and other antibiotics do not kill the bacteria causing an infection, it becomes harder to get rid of the infection. MRSA bacteria are more likely to develop when antibiotics are used too often or are not used correctly. Given enough time, bacteria can change so that these antibiotics no longer work well. This is why MRSA and other antibiotic- resistant bacteria are sometimes called "super bugs." Methicillin-resistant Staphylococcus aureus (MRSA) were first reported in the early 1960's and are now regarded as a major 
hospital acquired pathogen worldwide. The term methicillin resistant is historically used to describe resistance to any of this class of antimicrobials.

Resistance occurs when the organism has a mecA gene producing an altered penicillin binding protein, PBP2a (also known as PBP2') and either an oxacillin MIC of $2 \mathrm{mg} / \mathrm{l}$ or a methicillin MIC of $4 \mathrm{mg} / \mathrm{l}$. Infected and colonised patients are the reservoir of MRSA both in hospitals and the community with transmission generally being via contact with health workers. Effective, rapid laboratory diagnosis and susceptibility testing is critical in treating, managing and preventing MRSA infections. Therefore, Methicillin resistance requires the presence of the mec gene; strains lacking a mec gene are not methicillin resistant. Methicillin resistance is defined in the clinical microbiology laboratory as an oxacillin minimum inhibitory concentration $(\mathrm{MIC}) \geq 4 \mathrm{mcg} / \mathrm{mL}$ [7, 10]. Other methods of detection, such as the use of the cefoxitin disk or one of several polymerase chain reactions (PCR) to detect the mec gene, are also used. Isolates resistant to oxacillin or methicillin are also resistant to all beta-lactam agents including cephalosporins. MICs of 4 to $8 \mathrm{mcg} / \mathrm{mL}$ are considered to represent borderline or low level resistance.

The prevention of horizontal transmission of MRSA has become increasingly important as the prevalence of this pathogen increases. Oral carriage of MRSA may serve as a reservoir for recolonization of other body sites or for crossinfection to other patients or health care workers. At least two cases have been reported of cross-infection from a general dental practitioner to patients [7]. The practitioner had probably been colonised whilst a patient in hospital. Nursing homes are another important source of colonization and infection and two cases of acute parotitis caused by MRSA in elderly patients have been described [8]. Attempts are frequently made to eradicate carriage of MRSA from either patients or medical staff colonized by this organism. However, clinical experience has shown that oropharyngeal carriage of MRSA can be difficult to eradicates [9].

\section{MOLECULAR MECHANISM INVOLVED IN METHICILLIN RESISTANCE mec gene}

The presence of the mec gene is $\mathrm{s}$ total requirement for $\mathrm{S}$. aureus to express methicillin resistance. The mec gene is absent from susceptible strains and present in all resistant strains $[11,12]$. The structural component of the mec gene, mecA, encodes the penicillin binding protein $2 \mathrm{a}$ (PBP2A) that establishes resistance to methicillin and other semisynthetic penicillinase resistant beta-lactams. The mechanism of oxacillin resistance may be different in borderline resistant strains in which the mec gene is not present or is present in a very small resistant subpopulation.

There are genomes for several strains of MRSA have been published; three classes of pathogenicity islands and diverse possible superantigens have been identified [13-15]. The mec gene consists of a structural component, mecA, andtwo regulatory components that control expression of the gene. These include;

I. mecR1-mecI: is a negative regulator of mecA transcription. Mutations in this set of genes results in more highly resistant strains.

II. The beta-lactamase genes: blaI, blaRI, and blaZ which control expression of betalactamase and because of sequence similarity to the mecR1-mecI genes also can down regulate mecA gene transcription [16]. However, beta-lactamase produces resistance by a mechanism different from mec. It hydrolyzes the beta-lactam ring. Because this negative regulation is not tightly controlled (eg, it is leaky), expression of resistance following exposure to beta-lactams is relatively rapid. The looser control allows the mec gene to synthesize protein that under conditions of greater regulatory control would not be permitted.

Just to add on to the above mentioned regulatory genes, there are sequences of five auxiliary genes that can modify expression of methicillin resistance. These are known as the fem (factor essential for the expression of methicillin resistance) A to $\mathrm{E}$ genes.

\section{PENICILLIN BINDING PROTEIN 2a}

Penicillin binding proteins are peptidase enzymes located in the bacterial membrane that catalyze the transpeptidation reactions of peptidoglycan during cell wall synthesis. MecA encodes penicillin binding protein (PBP) $2 \mathrm{a}$, an inducible protein that establishes resistance to the semisynthetic penicillinase resistant beta-lactams: methicillin, nafcillin , oxacillin , and all cephalosporins $[17,18]$. In contrast to the other four PBPs (1-4), PBP2a has a low affinity for betalactam antibiotics. In susceptible staphylococcal isolates, the beta-lactams covalently bind to PBPs 1-3, thereby inactivating enzyme activity, preventing transpeptidation, and ultimately contributing to bacterial death. PBP2a, with its low affinity for the beta-lactams, can substitute for the enzymatic activity of these PBPs and allow completion of cell wall assembly. The resulting peptidoglycan has a structurally different muropeptide composition, a change that does not appear to affect cellular function [19]. 


\section{STAPHYLOCOCCAL CHROMOSOMAL}

\section{CASSETTE mec (SCCmec)}

The mec gene is part of a 21 to $67 \mathrm{~kb}$ mobile chromosomal element called the staphylococcal cassette chromosome (SCCmec). The majority of healthcareassociated (mostly nosocomial) MRSA clones is associated with SCCmec types I, II, and III and are multidrug resistant [20]. In contrast, most communityassociated MRSA (CA-MRSA) strains have type IV or V SCCmec and were formerly susceptible to other antibiotic families; this is no longer the case [21-25]. Methicillin resistance may reduce the virulence of healthcare-associated MRSA by interfering with agr quorum sensing [26]. In one study, healthcareassociated MRSA strains carrying SCCmec type II produced reduced amounts of cytolytic toxins as measured by an in vitro $\mathrm{T}$ cell survival assay and in vivo murine bacteremia model. Alteration of the cell wall appeared to affect the agr quorum sensing system resulting in diminished virulence. This effect has not been observed among community-associated MRSA isolates and may help explain the failure of HA-MRSA to spread into the community. Sequencing SCCmec from many MRSA strains has demonstrated at least six SCCmec types (I-VI) that vary in genetic makeup and size $[27,28]$. Transfer of SCCmec from MRSA into well-adapted strains of methicillin-susceptible $\mathrm{S}$. aureus (MSSA) has occurred on a number of occasions, resulting in new MRSA isolates that spread rapidly in healthcare institutions.

\section{ORIGIN IN COAGULASE NEGATIVE STAPHYLOCOCCI}

It is believed that the mec gene was acquired from these closely related staphylococcal species via a limited number of genetic events. The mec gene is essentially the same in all staphylococcal species. Several studies point to CoNS as the origin of methicillin resistance in Staphylococcus aureus. Segments of DNA from an insertion sequence found in CoNS (IS 1272) have been identified in MRSA [29, 30]. Insertion sequence elements are DNA segments that encode enzymes that allow for site-specific recombination. In addition, one study reported 88 percent amino acid homology for the MRSA mec gene in S. sciuri, another species of CoNS [31]. The presence of different insertion sequence fragments within the mec gene makes transposition a likely mechanism of transfer for the gene between species [32]. Sequencing of the MRSA strain, USA300, an epidemic clone of community-acquired MRSA, has shown that additional virulence and resistance genes have also been acquired from CoNS [33]. These genes include molecular variants of enterotoxin $\mathrm{Q}$ and $\mathrm{K}$ and a mobile element (the arginine catabolic mobile element, ACME) that encodes an arginine deaminase pathway and an oligopeptide permease system. The authors hypothesize these genes enable the strain to evade host immune responses and contribute to its ability to survive and spread in host tissue. The virulence of USA300 appears to be linked to the differential expression of selected virulence determinants that were already present in the progenitor strain (USA500) of USA300 [34].

\section{EXPRESSION OF METHICILLIN RESISTANCE}

Even though the presence in MRSA of the mec gene, the phenotypic expression of methicillin resistance varies. There are three different forms for the expression of methicillin resistance: homogeneous, heterogeneous, and borderline. For instance, under routine growth conditions $\left(37^{\circ} \mathrm{C}\right.$, unsupplemented media), $\geq 99.9$ percent of MRSA appear to be susceptible to the beta-lactams (eg, oxacillin 4 $\mathrm{mcg} / \mathrm{mL}$ ). However, if the cells are grown at 30 to $35^{\circ} \mathrm{C}$ or in the presence of 6.5 percent sodium chloride, they become more homogeneously resistant and express beta-lactam resistance at a much higher frequency [35]. It is also good to note that the growth of heterogeneous strains in the presence of a beta-lactam results in the selection of a homogeneous phenotype. Serial passage of these cells in the absence of antibiotic leads to slow reversion back to the heterogeneous state. A similar trend is evident in experimental endocarditis. It has been observed that when rabbits infected with MRSA are treateded with a beta-lactam results in a greater percentage of the total bacterial population being resistant than in untreated controls [36]. There was also a correlation between the potential efficacy of the antibiotic and its affinity for binding to PBP2a in vitro.

\section{fem genes}

The fem genes and other genes are necessary for the homogeneous expression of resistance [37]. These auxiliary genes affect different steps in the synthesis of peptidoglycan. Inactivation of these genes can convert a homogeneously resistant strain to a heterogeneous resistant one [38].

\section{Borderline resistance}

Borderline resistance refers to isolates that are at the margin of resistance with an MIC to methicillin of 4 to $8 \mathrm{mcg} / \mathrm{mL}$. This type of resistance may be due to one of several mechanisms. (a).Some strains with borderline resistance possess the mecA gene. In these strains, the resistant subpopulation may be extremely small and therefore more susceptible to beta-lactams. (b).In strains that lack the mecA gene (and therefore PBP2a), there may be alterations in or overexpression of the other PBPs, resulting in reduced affinity for betalactams or the availability of more enzyme for peptidoglycan synthesis. Overproduction of betalactamase with slow hydrolysis of the beta-lactam antibiotic has also been hypothesized as a potential mechanism for borderline resistance in mecA negative strains $[39,40]$.

\section{LABORATORY DETECTION}

The most accurate methods to detect MRSA are polymerase chain reaction (PCR) for detection of the mecA gene and latex agglutination tests for the 
protein product of mecA, penicillin binding protein $2 \mathrm{a}$ [41-44]. When these tests are not available, traditional microbiology laboratory techniques are acceptable, such as oxacillin -salt agar screening plates and cefoxitin disk diffusion tests.

\section{Culture}

Surveillance cultures are performed at body sites (mostly the anterior nares) that are frequently colonized with MRSA. The majority of patients with asymptomatic MRSA colonization will be detected by screening culture from the anterior nares (sensitivity 73 to 93 percent) [41-44]. The sensitivity can be increased by also screening open lesions, such as surgical wounds, pressure (decubitus) ulcers, and areas of skin breakdown.

In patients without open lesions, a one-year study of multisite screening (nares, rectum, and axilla) found that nares culture alone missed 27 percent of MRSA carriers [45]. Throat swabs also may be helpful. In a screening study of almost 3000 individuals for $\mathrm{S}$. aureus carriage, 37 percent had nasal carriage and 13 percent were colonized only in the throat, increasing the sensitivity of screening by 26 percent [46]. A similar increase in yield with throat swabs ( 22 percent) was seen in the small subset of MRSA carriers. Traditional methods used to process surveillance cultures take 48 to 72 hours to yield results. However, newly available techniques shorten the amount of time required to detect MRSA in surveillance cultures. A chromogenic selective agar containing cefoxitin detects a majority of MRSA isolates within 24 hours, while commercially available real-time PCR tests for mecA can detect MRSA within two hours [40].

\section{Antimicrobial susceptibility testing}

In the past, most healthcare-associated MRSA strains were multidrug resistant. Isolates that are resistant to oxacillin but remain susceptible to most non-beta-lactam agents (eg, trimethoprimsulfamethoxazole, clindamycin, and ciprofloxacin ) are usually community-associated MRSA. Such strains should be tested using a confirmatory test such as a mecA probe, PCR assay for mecA, oxacillin-salt agar screening plates, or cefoxitin disk diffusion tests.

Antibiotic susceptibility testing for methicillin resistance has been modified to enhance the detection of these isolates, a large number of which are heterogeneously resistant to methicillin. Susceptibility testing now includes use of the more stable oxacillin rather than methicillin disk, incubation at $\leq 35^{\circ} \mathrm{C}$ for 24 rather than 18 hours, and the incorporation of 6.5 percent sodium chloride into the media. It is important to remember that isolates resistant to oxacillin are also resistant to all beta-lactam agents including cephalosporins. Specific recommendations exist for the different methods of susceptibility testing such as automated turbidometric or disk diffusion assays [47].
In the future, it is likely that clinical isolates will be screened for methicillin resistance by polymerase chain reaction (PCR) or with probes specific for segments of the mec gene. Kits for the detection of the mec gene are becoming more common. Alternative approaches including screening with cefoxitin disks and the MRSA latex agglutination test $[48,49]$.

\section{TRANSMISSION}

Healthcare-associated methicillin-resistant S. aureus (HA-MRSA) strains are most commonly transmitted to patients via the transiently contaminated hands of healthcare workers. Hospitalized patients may also acquire HA-MRSA from contaminated environmental surfaces. Community-associated methicillin-resistant S. aureus (CA-MRSA) strains are most commonly transmitted by direct contact with a colonized or infected individual. At the community level, individuals may also acquire CA-MRSA by contact with contaminated fomites used by an affected individual. Among 188 household contacts of 148 patients known to be colonized with MRSA prior to hospital discharge, 19 percent acquired MRSA colonization, though none developed MRSA infection [50]. Older age and providing healthcare to the discharged patient were associated with MRSA acquisition. Adherence to infection control measures is critical for interrupting MRSA transmission.

\section{COLONIZATION}

Individual MRSA colonization is an important risk factor for subsequent development of MRSA infection. Individuals colonized with MRSA serve as a reservoir for transmission. MRSA can colonize the skin and nares of hospitalized patients, health care workers, and healthy individuals (up to 7 percent) [51-53]. Colonization increases the risk for MRSA infection. Colonization can occur in the following ways [54]:

- Contact with contaminated wounds or dressings of infected patients

- Contact with another individual's colonized intact skin

- Contact with contaminated inanimate objects

- Inhalation of aerosolized droplets from chronic nasal carriers

The anterior nares is the most common site of MRSA colonization [55-57]. Individuals with nasal MRSA carriage transmit MRSA more readily in the setting of concomitant sinus infection or upper respiratory infection $[58,59]$. A majority of individuals with nasal colonization are also colonized on other areas of intact skin including the hands, axillae, perineum, and umbilicus (in infants) [60-62]. Other potential sites of MRSA colonization include surgical wounds, decubitus ulcers, intravascular catheter sites and other invasive devices, throat, sputum, stool and the genitourinary tract. In one study of 71 hospitalized patients with S. aureus colonization, 67 percent had colonization of the gastrointestinal tract, which was 
associated with increased frequency of S. aureus skin colonization [63]. The durability of MRSA colonization can vary from a few days or weeks to up to several years [64].

\section{RECOMMENDATIONS}

To minimise the spread of MRSA, this review recommends the following measures to be observed:

I. Active surveillance cultures (ASC) identify the reservoir of asymptomatic, colonized patients to be placed on contact precautions with the goal of minimizing MRSA spread to other patients. While most agree that ASC with contact isolation is appropriate in the setting of an outbreak, the role of ASC for routine surveillance screening is a controversial issue of ongoing debate.

II. The use of active surveillance cultures has been shown to be cost-effective during ICU outbreaks and in high-risk MRSA transmission settings, although the cost-effectiveness of routine surveillance screening is not known.

III. We suggest that MRSA decolonization not be performed in the routine management of MRSA infections. Decolonization does not appear to be consistently effective for eliminating MRSA carriage, and emergence of resistance to agents used for decolonization will limit the utility of such protocols.

IV. We suggest performing decolonization in the setting of an MRSA outbreak, particularly if there is epidemiologic evidence pointing to transmission by one or more healthcare workers or among a specific patient population.

V. Additional important components for MRSA prevention and control include hand hygiene, attention to environmental cleaning and prudent antibiotic use both in the hospital and in the community.

\section{CONCLUSION}

In conclusion, the prevalence of MRSA isolation from hospitals, community, animals and their products has increased in different geographical locations. The continous vigilance of MRSA through monitor ing of newer strains, their characteristic, host specificity and transmission routes in each of the settings (HA-MRSA, CA-MRSA, LA-MRSA) will help in effective control of MRSA. MRSA is no longer infection acquired in the hospital alone, but rather in communities through contact with domesticated and wild animals as well as food products and the environment. Therefore, there is need for effective control of MRSA in all the settings and the avoidance of indiscriminate use of antibiotics to prevent further selection of resistance by microorganisms.

\section{REFERENCES}

1. Abdulgader, S. M. A., Shittu, A., Nicol, M. P., \& Kaba, M. (2014). Molecular epidemiology of methicillin-resistant Staphylococcus aureus in Africa: A systematic review of the published literature. International Journal of Infectious Diseases, 21, 107.

2. Abraham, E. P., \& Chain, E. (1940). An enzyme from bacteria able to destroy penicillin. Nature, 146(3713), 837-842.

3. Afroz, S., Kobayashi, N., Nagashima, S., Alam, M. M., Hossain, A. B., Rahman, M. A., ... \& Hossain, M. A. (2008). Genetic characterization of Staphylococcus aureus isolates carrying Panton-Valentine leukocidin genes in Bangladesh. Jpn J Infect Dis, 61(5), 393-6.

4. Aiken, A. M., Mutuku, I. M., Sabat, A. J., Akkerboom, V., Mwangi, J., Scott, J. A. G., ... \& Grundmann, H. (2014). Carriage of Staphylococcus aureus in Thika Level 5 Hospital, Kenya: a cross-sectional study. Antimicrobial resistance and infection control, 3(1), 22.

5. Aklilu, E., Zunita, Z., Hassan, L., \& Chen, H. C. (2010). Phenotypic and genotypic characterization of methicillin-resistant Staphylococcus aureus (MRSA) isolated from dogs and cats at University Veterinary Hospital, Universiti Putra Malaysia. Trop Biomed, 27(3), 483-492.

6. Allen, K. D., Anson, J. J., Parsons, L. A., \& Frost, N. G. (1997). Staff carriage of methicillinresistant Staphylococcus aureus (EMRSA 15) and the home environment: a case report. Journal of Hospital Infection, 35(4), 307311.

7. Martin, M. V., \& Hardy, P. (1991). Two cases of oral infection by methicillin-resistant Staphylococcus aureus. British dental journal, 170(2), 63-64.

8. Rousseau, P. (1990). Acute suppurative parotitis. Journal of the American Geriatrics Society, 38(8), 897-898.

9. Ayliffe, G. A. J., Buckles, M. A., Casewell, M. W., Cookson, B. D., Cox, R. A., Duckworth, G. J., ... \& Tebbs, E. (1998). Revised guidelines for the control of methicillin-resistant Staphylococcus aureus infection in hospitals: report of a combined working party of the British Society for Antimicrobial Chemotherapy, the Hospital Infection Society and the Infection Control Nurses Association. Journal of Hospital Infection, 39(4), 253-290.

10. Clinical and Laboratory Standards Institute. (2006). Performance Standards for Antimicrobial Susceptibility Testing: Sixteenth Informational Supplement. M100-S16 Methods for dilution antimicrobial susceptibility tests for bacteria that grow aerobically: Approved Standard. Vol 26. No 3. CLSI, Wayne, 
Pennsylvania, USA.

11. Inglis, B., Matthews, P. R., \& Stewart, P. R. (1988). The expression in Staphylococcus aureus of cloned DNA encoding methicillin resistance. Microbiology, 134(6), 1465-1469.

12. Tesch, W., Strässle, A., Berger-Bächi, B., O'Hara, D., Reynolds, P., \& Kayser, F. H. (1988). Cloning and expression of methicillin resistance from Staphylococcus epidermidis in Staphylococcus carnosus. Antimicrobial agents and chemotherapy, 32(10), 1494-1499.

13. Kuroda, M., Ohta, T., \& Uchiyama, I. (2001). Whole genome sequencing of meticillin-resistant Staphylococcus aureus. Lancet, 357:1225.

14. Baba, T., Takeuchi, F., Kuroda, M., Yuzawa, H., Aoki, K. I., Oguchi, A., ... \& Hiramatsu, K. (2002). Genome and virulence determinants of high virulence community-acquired MRSA. The Lancet, 359(9320), 1819-1827.

15. Diep, B. A., Gill, S. R., Chang, R. F., Phan, T. H., Chen, J. H., Davidson, M. G., ... \& PerdreauRemington, F. (2006). Complete genome sequence of USA300, an epidemic clone of community-acquired meticillin-resistant Staphylococcus aureus. The Lancet, 367(9512), 731-739.

16. Zhang, H. Z., Hackbarth, C. J., Chansky, K. M., \& Chambers, H. F. (2001). A proteolytic transmembrane signaling pathway and resistance to $\beta$-lactams in staphylococci. Science, 291(5510), 1962-1965.

17. Hartman, B. J., \& Tomasz, A. (1984). Lowaffinity penicillin-binding protein associated with beta-lactam resistance in Staphylococcus aureus. Journal of bacteriology, 158(2), 513516.

18. Utsui, Y. U. K. I. O., \& Yokota, T. A. K. E. S. H. I. (1985). Role of an altered penicillinbinding protein in methicillin-and cephemresistant Staphylococcus aureus. Antimicrobial agents and chemotherapy, 28(3), 397-403.

19. de Jonge, B. L., \& Tomasz, A. (1993). Abnormal peptidoglycan produced in a methicillin-resistant strain of Staphylococcus aureus grown in the presence of methicillin: functional role for penicillin-binding protein $2 \mathrm{~A}$ in cell wall synthesis. Antimicrobial agents and chemotherapy, 37(2), 342-346.

20. Michel, M., \& Gutmann, L. (1997). Methicillinresistant Staphylococus aureus and vancomycinresistant enterococci: therapeutic realities and possibilities. The Lancet, 349(9069), 1901-1906.

21. Daum, R. S., Ito, T., Hiramatsu, K., Hussain, F., Mongkolrattanothai, K., Jamklang, M., \& BoyleVavra, S. (2002). A novel methicillin-resistance cassette in community-acquired methicillinresistant Staphylococcus aureus isolates of diverse genetic backgrounds. The Journal of infectious diseases, 186(9), 1344-1347.

22. Ma, X. X., Ito, T., Tiensasitorn, C., Jamklang,
M., Chongtrakool, P., Boyle-Vavra, S., ... \& Hiramatsu, K. (2002). Novel type of staphylococcal cassette chromosome mec identified in community-acquired methicillinresistant Staphylococcus aureus strains. Antimicrobial agents and chemotherapy, 46(4), 1147-1152.

23. Naimi, T. S., LeDell, K. H., Como-Sabetti, K., Borchardt, S. M., Boxrud, D. J., Etienne, J., ... \& Lynfield, R. (2003). Comparison of communityand health care-associated methicillin-resistant Staphylococcus aureus infection. Jama, 290(22), 2976-2984.

24. Salmenlinna, S., Lyytikäinen, O., \& VuopioVarkila, J. (2002). Community-acquired methicillin-resistant Staphylococcus aureus, Finland. Emerging infectious diseases, 8(6), 602.

25. Sattler, C. A., Mason Jr, E. O., \& Kaplan, S. L. (2002). Prospective comparison of risk factors and demographic and clinical characteristics of community-acquired, methicillin-resistant versus methicillin-susceptible Staphylococcus aureus infection in children. The Pediatric infectious disease journal, 21(10), 910-916.

26. Rudkin, J. K., Edwards, A. M., Bowden, M. G., Brown, E. L., Pozzi, C., Waters, E. M., ... \& Massey, R. C. (2012). Methicillin resistance reduces the virulence of healthcare-associated methicillin-resistant Staphylococcus aureus by interfering with the agr quorum sensing system. Journal of Infectious Diseases, 205(5), 798-806.

27. Oliveira, D. C., Tomasz, A., \& de Lencastre, H. (2001). The evolution of pandemic clones of methicillin-resistant Staphylococcus aureus: identification of two ancestral genetic backgrounds and the associated mec elements. Microbial Drug Resistance, 7(4), 349361.

28. Ito, T., Ma, X. X., Takeuchi, F., Okuma, K., Yuzawa, H., \& Hiramatsu, K. (2004). Novel type V staphylococcal cassette chromosome mec driven by a novel cassette chromosome recombinase, ccrC. Antimicrobial agents and chemotherapy, 48(7), 2637-2651.

29. Archer, G. L., \& Niemeyer, D. M. (1994). Origin and evolution of DNA associated with resistance to methicillin in staphylococci. Trends in microbiology, 2(10), 343-347.

30. Archer, G. L., Niemeyer, D. M., Thanassi, J. A., \& Pucci, M. J. (1994). Dissemination among staphylococci of DNA sequences associated with methicillin resistance. Antimicrobial Agents and Chemotherapy, 38(3), 447-454.

31. Wu, S., Piscitelli, C., de Lencastre, H. E. R. M. I. N. I. A., \& Tomasz, A. (1996). Tracking the evolutionary origin of the methicillin resistance gene: cloning and sequencing of a homologue of mecA from a methicillin susceptible strain of Staphylococcus sciuri. Microbial drug 
resistance, 2(4), 435-441.

32. Chambers, H. F. (1997). Methicillin resistance in staphylococci: molecular and biochemical basis and clinical implications. Clinical microbiology reviews, 10(4), 781-791.

33. Diep, B. A., Gill, S. R., Chang, R. F., Phan, T. H., Chen, J. H., Davidson, M. G., ... \& PerdreauRemington, F. (2006). Complete genome sequence of USA300, an epidemic clone of community-acquired meticillin-resistant Staphylococcus aureus. The Lancet, 367(9512), 731-739.

34. Li, M., Diep, B. A., Villaruz, A. E., Braughton, K. R., Jiang, X., DeLeo, F. R., ... \& Otto, M. (2009). Evolution of virulence in epidemic community-associated methicillin-resistant Staphylococcus aureus. Proceedings of the National Academy of Sciences, 106(14), 58835888.

35. Chambers, H. F. (1997). Methicillin resistance in staphylococci: molecular and biochemical basis and clinical implications. Clinical microbiology reviews, 10(4), 781-791.

36. Chambers, H. F., Sachdeva, M., \& Kennedy, S. (1990). Binding Affinity for Penicillin-Binding Protein 2a Correlates with In Activity of $\beta$ Lactan Antibiotics against Methicillin-Resistant Staphylococcus aureus. Journal of Infectious Diseases, 162(3), 705-710.

37. De Lencastre, H., \& Tomasz, A. (1994). Reassessment of the number of auxiliary genes essential for expression of high-level methicillin resistance in Staphylococcus aureus. Antimicrobial agents and chemotherapy, 38(11), 2590-2598.

38. Berger-Bächi, B. (1994). Expression of resistance to methicillin. Trends in microbiology, 2(10), 389-393.

39. Tomasz, A., Drugeon, H. B., De Lencastre, H. M., Jabes, D., McDougall, L., \& Bille, J. (1989). New mechanism for methicillin resistance in Staphylococcus aureus: clinical isolates that lack the PBP 2a gene and contain normal penicillinbinding proteins with modified penicillinbinding capacity. Antimicrobial Agents and Chemotherapy, 33(11), 1869-1874.

40. Henze, U. U., \& Berger-Bächi, B. R. I. G. I. T. T. E. (1995). Staphylococcus aureus penicillinbinding protein 4 and intrinsic beta-lactam resistance. Antimicrobial agents and chemotherapy, 39(11), 2415-2422.

41. Harbarth, S., Fankhauser, C., Schrenzel, J., Christenson, J., Gervaz, P., Bandiera-Clerc, C., ... \& Pittet, D. (2008). Universal screening for methicillin-resistant Staphylococcus aureus at hospital admission and nosocomial infection in surgical patients. Jama, 299(10), 1149-1157.

42. Francois, P., Bento, M., Renzi, G., Harbarth, S., Pittet, D., \& Schrenzel, J. (2007). Evaluation of three molecular assays for rapid identification of methicillin-resistant Staphylococcus aureus. Journal of clinical microbiology, 45(6), 2011-2013.

43. Stamper, P. D., Cai, M., Howard, T., Speser, S., \& Carroll, K. C. (2007). Clinical validation of the molecular BD GeneOhm StaphSR assay for direct detection of Staphylococcus aureus and methicillin-resistant Staphylococcus aureus in positive blood cultures. Journal of clinical microbiology, 45(7), 2191-2196.

44. Hogg, G. M., McKenna, J. P., \& Ong, G. (2008). Rapid detection of methicillin-susceptible and methicillin-resistant Staphylococcus aureus directly from positive BacT/Alert ${ }^{\circledR}$ blood culture bottles using real-time polymerase chain reaction: evaluation and comparison of 4 DNA extraction methods. Diagnostic microbiology and infectious disease, 61(4), 446-452.

45. Misawa, Y., Saito, R., Moriya, K., Koike, K., Yoshida, A., Okuzumi, K., ... \& Okada, M. (2007). Application of loop-mediated isothermal amplification technique to rapid and direct detection of methicillin-resistant Staphylococcus aureus (MRSA) in blood cultures. Journal of Infection and Chemotherapy, 13(3), 134-140.

46. Gröbner, S., \& Kempf, V. A. J. (2007). Rapid detection of methicillin-resistant staphylococci by real-time PCR directly from positive blood culture bottles. European Journal of Clinical Microbiology \& Infectious Diseases, 26(10), 751-754.

47. Thomas, L. C., Gidding, H. F., Ginn, A. N., Olma, T., \& Iredell, J. (2007). Development of a real-time Staphylococcus aureus and MRSA (SAM-) PCR for routine blood culture. Journal of microbiological methods, 68(2), 296-302.

48. Wolk, D. M., Struelens, M. J., Pancholi, P., Davis, T., Della-Latta, P., Fuller, D., ... \& Chapin, K. (2009). Rapid detection of Staphylococcus aureus and methicillin-resistant $\mathrm{S}$. aureus (MRSA) in wound specimens and blood cultures: multicenter preclinical evaluation of the Cepheid Xpert MRSA/SA skin and soft tissue and blood culture assays. Journal of clinical microbiology, 47(3), 823-826.

49. Stratidis, J., Bia, F. J., \& Edberg, S. C. (2007). Use of real-time polymerase chain reaction for identification of methicillin-resistant Staphylococcus aureus directly from positive blood culture bottles. Diagnostic microbiology and infectious disease, 58(2), 199-202.

50. Lucet, J. C., Paoletti, X., Demontpion, C., Degrave, M., Vanjak, D., Vincent, C., ... \& Nicolas-Chanoine, M. H. (2009). Carriage of methicillin-resistant Staphylococcus aureus in home care settings: prevalence, duration, and transmission to household members. Archives of internal medicine, 169(15), 1372-1378.

51. Kuehnert, M. J., Kruszon-Moran, D., Hill, H. A., McQuillan, G., McAllister, S. K., Fosheim, G., 
... \& Tenover, F. C. (2006). Prevalence of Staphylococcus aureus nasal colonization in the United States, 2001-2002. Journal of Infectious Diseases, 193(2), 172-179.

52. Kenner, J., O'Connor, T., Piantanida, N., Fishbain, J., Eberly, B., Viscount, H., ... \& Hospenthal, D. (2003). Rates of carriage of methicillin-resistant and methicillin-susceptible Staphylococcus aureus in an outpatient population. Infection Control \& Hospital Epidemiology, 24(6), 439-444.

53. Reboli, A. C., John, J. F., Platt, C. G., \& Cantey, J. R. (1990). Methicillin-resistant Staphylococcus aureus outbreak at a Veterans' Affairs Medical Center: importance of carriage of the organism by hospital personnel. Infection Control \& Hospital Epidemiology, 11(6), 291296.

54. Coello, R., Jiménez, J., García, M., Arroyo, P., Minguez, D., Fernandez, C., ... \& Gaspar, C. (1994). Prospective study of infection, colonization and carriage of methicillin-resistant Staphylococcus aureus in an outbreak affecting 990 patients. European Journal of Clinical Microbiology and Infectious Diseases, 13(1), 7481.

55. Sanford, M. D., Widmer, A. F., Bale, M. J., Jones, R. N., \& Wenzel, R. P. (1994). Efficient detection and long-term persistence of the carriage of methicillin-resistant Staphylococcus aureus. Clinical Infectious Diseases, 19(6), 1123-1128.

56. Reagan, D. R., Doebbeling, B. N., Pfaller, M. A., Sheetz, C. T., Houston, A. K., Hollis, R. J., \& Wenzel, R. P. (1991). Elimination of coincident Staphylococcus aureus nasal and hand carriage with intranasal application of mupirocin calcium ointment. Annals of internal medicine, 114(2), 101-106.

57. Boyce, J. M., Havill, N. L., \& Maria, B. (2005). Frequency and possible infection control implications of gastrointestinal colonization with methicillin-resistant aureus. Journal of clinical microbiology, 43(12), 5992-5995.

58. Boyce, J. M., Opal, S. M., Potter-Bynoe, G., \& Medeiros, A. A. (1993). Spread of methicillinresistant Staphylococcus aureus in a hospital after exposure to a health care worker with chronic sinusitis. Clinical infectious diseases, 17(3), 496-504.

59. Sherertz, R. J., Reagan, D. R., Hampton, K. D., Robertson, K. L., Streed, S. A., Hoen, H. M., \& Thomas, R. (1996). A cloud adult: the Staphylococcus aureus-virus interaction revisited. Annals of internal medicine, 124(6), 539-547.

60. Cook, H. A., Furuya, E. Y., Larson, E., Vasquez, G., \& Lowy, F. D. (2007). Heterosexual transmission of community-associated methicillin-resistant Staphylococcus aureus. Clinical Infectious Diseases, 44(3), 410413.

61. Chen, K. T., Huard, R. C., Della-Latta, P., \& Saiman, L. (2006). Prevalence of methicillinsensitive and methicillin-resistant Staphylococcus aureus in pregnant women. Obstetrics \& Gynecology, 108(3), 482487.

62. Rohr, U., Wilhelm, M., Muhr, G., \& Gatermann, S. (2004). Qualitative and (semi) quantitative characterization of nasal and skin methicillinresistant Staphylococcus aureus carriage of hospitalized patients. International journal of hygiene and environmental health, 207(1), 5155.

63. Bhalla, A., Aron, D. C., \& Donskey, C. J. (2007). Staphylococcus aureus intestinal colonization is associated with increased frequency of $\mathrm{S}$. aureus on skin of hospitalized patients. BMC infectious diseases, 7(1), 1-7.

64. Cookson, B. B. M. I. M. W., Peters, B., Webster, M., Phillips, I., Rahman, M., \& Noble, W. (1989). Staff carriage of epidemic methicillinresistant Staphylococcus aureus. Journal of clinical microbiology, 27(7), 1471-1476.

Cite This Article: Iddah, M. Ali \& Peter K. Nyongesa (2021). Microbiology of Methicillin Resistant Staphylococcus Aureus: A Review. EAS J Parasitol Infect Dis, 3(2), 23-30. 